\title{
Promoting Neurodiversity in Engineering through Undergraduate Research Opportunities for Students with ADHD
}

\section{Miss Alexandra Hain, University of Connecticut}

Alexandra Hain is a $\mathrm{PhD}$ student at the University of Connecticut studying structural engineering. She received her Bachelor of Science in Civil Engineering in 2015 from the University of Connecticut. She has an interest in engineering education and served as the program manager for the REU Site: Research Experience in Cyber and Civil Infrastructure Security for Students with ADHD: Fostering Innovation during summer 2016 and 2017.

\section{Dr. Arash E. Zaghi, University of Connecticut}

Arash E. Zaghi is an Assistant Professor in the Department of Civil and Environmental Engineering at the University of Connecticut. He received his PhD in 2009 from the University of Nevada, Reno, and continued there as a Research Scientist. His latest research endeavor is on creativity and engineering education, with a focus on the unique potential of students with ADHD. Supported by multiple grants from the National Science Foundation, his research was highlighted the American Society of Engineering Education's Prism Magazine. He received a CAREER Award in 2016 to study the significance of neurodiversity in developing a creative engineering workforce.

Ms. Christa L. Taylor 


\title{
Promoting Neurodiversity in Engineering through Undergraduate Research Opportunities for Students with ADHD
}

\begin{abstract}
Promoting diversity in engineering education has been a major initiative of ASEE in recent years, and may contribute to greater social equity, reduced opportunity costs, and greater creativity in the field of engineering. Indeed, there is ample evidence that the inclusion of women and minorities improves the productivity and creativity of teams. However, there is little awareness of the potential contributions of neurodiverse individuals, such as those with Attention Deficit Hyperactivity Disorder (ADHD). ADHD has been shown to be associated with creativity, innovation, and risk-taking. While these traits are all potential assets in the field of engineering, individuals with ADHD are extremely underrepresented in engineering programs. Too often, nontraditional thinkers struggle within the confines of the traditional engineering education curriculum. Providing these students opportunities to learn in a style that is more consistent with their unique strengths may positively affect the recruitment and retention of those with diverse cognitive styles. To promote the inclusion of students with ADHD in engineering, and thereby increase the diversity of the field, a specialized Research Experience for Undergraduates (REU) Site has been funded by the NSF Division of Engineering Education and Centers. This site provided students with ADHD an opportunity to engage in research outside the confines of the traditional engineering curriculum and interact with other students facing similar challenges. This paper presents quantitative and qualitative findings from a semi-structured interview and postprogram survey of the students' experiences. Overall, the major findings suggest that participating in the program enhanced students' 1) interest in engineering research, 2) interest in pursuing graduate studies in engineering, and 3) feelings of belonging in engineering. For instance, all participants $(N=10)$ responded either "agree" or "strongly agree" to statements reflecting that attending the REU site increased their interest in research and in pursuing graduate studies. Responses to open-ended items on the survey, as well as responses during interviews, indicated that attending the REU site enhanced students' feelings of belonging, which has been shown to positively influence persistence in engineering education. Understanding the challenges and potential of students with ADHD characteristics in engineering programs is needed to stem attrition in engineering education and promote cognitive diversity in the field. The implications of these findings for promoting inclusion and diversity in engineering and suggestions for educators to make courses more inclusive for neurodiverse students are discussed.
\end{abstract}

\section{Introduction}

Promoting diversity in engineering education has been a major initiative of ASEE in recent years, and may contribute to greater social equity, reduced opportunity costs, and greater creativity in the field of engineering. Engineering problems are becoming more complex, and demand analytical problem-solving, collaboration, and creativity. These problems are no longer only technicalsolution-focused; innovative solutions require understanding the problem in the context of economy, culture, sustainability and society. As such, we require a diverse engineering workforce to better tackle the multifaceted challenges of the future. Indeed, there is ample evidence that the 
inclusion of women and minorities improves the productivity and creativity of teams ${ }^{1-3}$. However, there is little awareness of the potential contributions of neurodiverse individuals, such as those with Attention Deficit Hyperactivity Disorder (ADHD).

ADHD is a neuropsychological condition characterized by a persistent pattern of inattention, hyperactivity, and/or impulsivity (American Psychological Association, 2013). It has been estimated that up to $4 \%$ of college students have been diagnosed with ADHD ${ }^{4}$. Individuals with ADHD are less likely to attend college than those without ${ }^{5}$ and those that do enroll tend to have lower grade point averages (GPA) and are more likely to be on academic probation ${ }^{6,7}$. Given that adults with ADHD score similarly on IQ tests as those without, when the groups have similar educational levels ${ }^{8}$, these outcomes are likely not due to differences in intellectual ability. Instead, symptoms of ADHD, including short attention span and difficulties with working memory, may contribute to academic struggles by causing greater difficulty with timed tests, taking longer to complete assignments, and feeling like one has to work harder than peers to achieve good grades ${ }^{9}$. However, ADHD has also been found to be associated with creativity, innovation, and risktaking $^{10-13}$. Because of these strengths, and suggestions that other symptoms may have been evolutionarily advantageous, it has been suggested that ADHD should be viewed as a form of neurodiversity, a natural variation in brain processes, rather than a disorder ${ }^{14-18}$. While the strengths associated with ADHD are potential assets in the field of engineering ${ }^{19,20}$, individuals with ADHD are extremely underrepresented in engineering programs ${ }^{21}$.

Too often, nontraditional thinkers struggle within the confines of the traditional engineering education curriculum. For instance, Bernold, Spurlin, and Anson (2007) found that students' thinking styles predicted persistence and GPA in engineering. Students who prefer listening and discussing ideas in an environment that encourages divergent thinking and subjectivity (i.e., a "why" style) or prefer hands-on trial-and-error and thought-provoking discussions in an environment that encourages originality (i.e., a "what-if" style) are more likely to have lower GPAs than students who prefer more structured styles of learning. These more concrete learning methods include critiquing information, creating theories from abstract facts, and verifying data (i.e., a "what" style) or preferring solo experimentation involving straightforward, objective thinking that leads to a measurable product (i.e., a "how" style). Students with a "why" or "what-if" thinking style were also more likely to leave engineering. This lack of support for cognitively diverse thinking styles may also explain why ADHD students are underrepresented in undergraduate engineering programs, with one study finding that only $3 \%$ of students with ADHD pursued engineering $^{21}$. Providing these students opportunities to learn in a style that is more consistent with their unique strengths may positively affect the recruitment and retention of those with diverse cognitive styles.

To promote the inclusion of students with ADHD in engineering, and thereby increase the diversity of the field, a specialized Research Experience for Undergraduates (REU) Site has been funded by the NSF Division of Engineering Education and Centers. This site provided students with ADHD an opportunity to engage in research outside the confines of the traditional engineering curriculum and interact with other students facing similar challenges. This paper presents quantitative and qualitative findings from a semi-structured interview and post-program survey of the students' experiences. 


\section{Research Experience for Undergraduate (REU) Site}

Program participants were six male and four female undergraduate engineering majors who had been previously diagnosed with ADHD. Participants were from universities across the U.S., with $50 \%$ receiving formal accommodations for their ADHD at their home university. The distribution of majors was as follows: Electrical Engineering = 3, Mechanical Engineering $=2$, Computer Science Engineering $=3$, Chemical Engineering $=1$, and Engineering Physics $=1$. Two participants indicated a dual major: one with philosophy and one with mathematics.

The program combined a ten-week traditional summer REU research experience with close mentorship, specially designed seminars, workshops, and roundtable discussions to address the strengths and needs of participants. The specific objectives of this REU Site were to:

- Provide an in-depth undergraduate research experience in a project related to cyber or physical infrastructure security while promoting the importance of an interdisciplinary view of security for interconnected, interdependent, and complex infrastructure.

- Promote advances by increasing the number of individuals with interdisciplinary expertise in cyber and physical security of critical infrastructure.

- Promote creativity as an essential component in security-related problem solving by encouraging approaches that are novel, transformative, and multidisciplinary.

- Capitalize on the strengths of an underserved group of students by encouraging students with ADHD to pursue research and advanced study in engineering.

- Increase the participation of a significantly underrepresented group of students who have the potential to profoundly impact the field but are at high risk of academic failure.

Each student was assigned a focused research project relating to both their interests and majors and was mentored by a dedicated faculty and graduate student. Each Friday afternoon of the program, the students participated in either roundtable discussions, brainstorming meetings, seminars, or workshops. These activities were updated based on feedback from the 2015 and 2016 participants. Roundtable discussions with the Principal Investigator (PI) helped form an environment of trust and respect which promoted student participation. These discussions focused on experiences within engineering programs, creative potential, and challenges associated with ADHD. Brainstorming meetings and hands-on activities allowed students to explore innovative ideas without confining guidelines or rules. The purpose of the discussions was to stimulate conversation among peers. The PI and program manager acted only to keep the discussion on topic and ensure that all students had an opportunity to speak if they wished to do so. Seminars on twiceexceptional education and creativity were included. Workshops were presented on responsible conduct of research and ethics, graduate school, preparing for the GRE exam, and technical writing. Preparation for graduate school was a key theme throughout the program; the topic was addressed in several workshops, brainstorming meetings and seminars. Bringing in outside experts was successful in increasing the participants' self-awareness while expanding their knowledge of possibilities following their completion of their undergraduate degree. 


\section{Data Collection}

Following the final day of the program, participants were sent a link to complete an online postprogram survey via SurveyMonkey platform. The survey contained 40 multiple closed-ended questions about participants' experiences with engineering education and with the REU site, followed by three open-ended questions.

Eight of the participants also volunteered to participate in a semi-structured interview (Male $=5$, Female= 3). Each participant was interviewed individually by a research specialist (a $\mathrm{PhD}$ candidate in psychology). The interviews were conducted in a private office and lasted approximately one hour. Students answered a series of questions about their perceptions of their engineering program, how their educational experiences and learning of technical subjects is influenced by ADHD, and how learning through conducting research compares to traditional classroom-based learning.

\section{Results}

Survey responses suggest that participating in the program enhanced students' 1) interest in engineering research, 2) interest in pursuing graduate studies in engineering, and 3) feelings of belonging in engineering. When prompted to answer how likely they were to pursue a series of possible avenues after graduation (Table 1), all participants indicated the likelihood that they would attend graduate school in engineering in the upper range of the scale (i.e., responses ranged from 4 to 6 on a 7 -point scale).

Table 1. Descriptive statistics for responses to the prompt "After graduation, I intend to..."

\begin{tabular}{lllll}
\hline Item & Mean & SD & Min. & Max. \\
\hline pursue graduate studies in the field of engineering. & 5.10 & 0.74 & 4.00 & 6.00 \\
pursue graduate studies in another field. & 2.20 & 0.92 & 1.00 & 4.00 \\
work in the field of engineering. & 4.40 & 1.26 & 2.00 & 6.00 \\
work in another field. & 2.30 & 1.25 & 1.00 & 4.00 \\
establish a startup company. & 3.70 & 1.57 & 1.00 & 6.00 \\
\hline
\end{tabular}

Note. $N=10$, scale ranged from 1 (extremely unlikely) to 6 (extremely likely)

Indeed, pursuing graduate studies in engineering had the highest mean response of the group of items $(\mathrm{M}=5.10, \mathrm{SD}=.74)$. Participants also indicated that they were more likely to work in the field of engineering $(\mathrm{M}=4.40, \mathrm{SD}=1.26)$ than they were to pursue work in a different field $(\mathrm{M}=$ $2.30, \mathrm{SD}=1.25)$ or to pursue graduate studies in a different field $(\mathrm{M}=2.20, \mathrm{SD}=.92)$. Responses to a series of questions asking participants how much they agreed to statements about the REU site (Table 2) demonstrate that these intentions were directly influenced by their experiences at the REU site. 
Table 2. Descriptive statistics for select questions about the REU site.

\begin{tabular}{lcccc}
\hline & Mean & SD & Min. & Max. \\
\hline $\begin{array}{l}\text { Attending the REU program increased my interest } \\
\text { in engineering. }\end{array}$ & 5.50 & .53 & 5.00 & 6.00 \\
$\begin{array}{l}\text { I am interested in staying involved in engineering } \\
\text { research. }\end{array}$ & 5.50 & .71 & 4.00 & 6.00 \\
$\begin{array}{l}\text { This REU program helped me improve my } \\
\text { academic performance. }\end{array}$ & 4.90 & 1.1 & 3.00 & 6.00 \\
$\begin{array}{l}\text { Participating in research has improved my interest } \\
\text { in engineering. }\end{array}$ & 5.40 & .70 & 4.00 & 6.00 \\
$\begin{array}{l}\text { This REU experience has increased my interest in } \\
\text { pursuing graduate school. }\end{array}$ & 5.70 & .48 & 5.00 & 6.00
\end{tabular}

Note. $N=10$, scale ranged from 1 (strongly disagree) to 6 (strongly agree)

All participants responded either "agree" or "strongly agree" to statements reflecting that attending the REU site increased their interest in research $(\mathrm{M}=5.50, \mathrm{SD}=.71)$ and in pursuing graduate studies in engineering $(\mathrm{M}=5.70, \mathrm{SD}=.48)$. That the REU site experience had a significant impact on these intentions is also reflected in participants' responses to the open-ended questions on the survey:
"Before contact with the CCIS REU, my plan consisted of: Graduate with a somewhat reasonable GPA and try to find a job with a BSEE without even considering a MS or PhD in any major. This REU has forced me to reevaluate those plans." (REU site participant, Male, open-ended survey response)
"I entered into the program after nearly failing out of college. I didn't have any confidence that I would be able to complete the research or the rest of my time studying for my... degree. I realized a few weeks into the program that I greatly enjoyed the control and creativity I was allowed to exercise on the research project. I enjoyed the people I worked with and became friends with the people in my program, both students and mentors. After I completed my research, I realized that somewhere along the way I realized that I could handle the research and I could handle the problems that had almost stopped me last year at college." (REU site participant, Male, open-ended survey response)

Participants' relatively lower response $(\mathrm{M}=4.90, \mathrm{SD}=1.10)$ to the statement "This REU helped me improve my academic performance" demonstrates that the REU site experience was beneficial in promoting the inclusion of these students in engineering, regardless of its perceived impact on their academic performance. Because the REU site was heavily focused on research, it is important 
to understand what specific aspects of conducting research the participants preferred, to understand how to implement these factors in future programs and in the existing engineering curriculum. Therefore, participants were asked to indicate how much they agreed or disagreed with a series of statements following the prompt "One of the best things about doing engineering research is being able to..." (Table 3).

Table 3. Descriptive statistics for responses to the prompt "One of the best things about doing engineering research is being able to...”

\begin{tabular}{lllll}
\hline Item & Mean & SD & Min. & Max. \\
\hline make mistakes. & 4.70 & 0.95 & 3.00 & 6.00 \\
follow tangents. & 5.00 & 1.05 & 3.00 & 6.00 \\
move about freely when working. & 5.00 & 0.67 & 4.00 & 6.00 \\
come up with my own way of solving a problem. & 5.30 & 1.06 & 3.00 & 6.00 \\
work with others. & 4.70 & 0.82 & 4.00 & 6.00 \\
solve open-ended problems. & 5.30 & 0.67 & 4.00 & 6.00 \\
do a project without being graded. & 5.20 & 1.03 & 3.00 & 6.00 \\
think deeply about something interesting. & 5.40 & 0.70 & 4.00 & 6.00 \\
work without specific instructions. & 5.50 & 0.71 & 4.00 & 6.00 \\
create something of value. & 5.50 & 0.71 & 4.00 & 6.00 \\
\hline
\end{tabular}

Note. $N=10$, scale ranged from 1 (strongly disagree) to 6 (strongly agree)

The highest mean ratings of the responses were "create something of value" $(\mathrm{M}=5.50, \mathrm{SD}=.71)$, "work without specific instructions" $(\mathrm{M}=5.50, \mathrm{SD}=.71)$, and "think deeply about something interesting” ( $\mathrm{M}=5.40, \mathrm{SD}=.70)$. Several participants also commented on these issues during the semi-structured interviews:

"That's the like, most exciting thing, is like, really learning something, and like, showing all the work that I've done. Like, presenting it, and people getting excited about it, 'cause then I get more excited about it, and then I want to do more stuff with it..." (REU site participant, Female, interview response)

“...the classroom work, like even the labs, are very like, okay, do this, measure this, you should get this result. With this, it's kind of like, okay, uh... solve this problem. It's a lot more open-ended. And, I think it's helping me gain a better understanding." (REU site participant, Male, interview response)

Responses to open-ended items on the survey, as well as responses during interviews, indicated that attending the REU site enhanced students' feelings of belonging, which has been shown to positively influence persistence in engineering education ${ }^{23}$ :

"I gained a great deal of self confidence in myself and in my abilities as an engineer and a student." (REU site participant, Male, open-ended survey response) 
“... I'm a lot more, like, self-confident, and I feel like I understand... that I understand things better than I, I thought I did, 'cause I thought that I was just dumb, and that I didn't know what I was doing in classes and stuff. Then when I realized that it was just the way people normally taught wasn't a way that I could learn, I started to feel a little bit better about it. And I definitely got that from, like, being here, like, talking to everyone, and being, like, yeah, we hate it, too. Yeah, we feel the same way, yeah. It's like, we have a lot more similarities than, like, I thought I could have with people. So that, like, definitely helped a lot." (REU site participant, Female, interview response)

\section{Discussion and Conclusions}

Understanding the challenges and potential of students with ADHD characteristics in engineering programs is needed to stem attrition in engineering education and promote cognitive diversity in the field. Teaching and learning within the engineering education pipeline has traditionally followed a one-size-fits-all approach, with a single set of instructions and a single-mode evaluation method, regardless of cognitive diversity and differences in aptitude, interests, and strengths. Subjecting students to the stringent approach common in traditional engineering programs may discourage them and fail to help them discover their full potential. Furthermore, diverse thinkers may not be attracted to or retained within such programs. For this reason, The National Academy of Engineering (NAE) has identified the advancing of personalized learning as one of the 14 Grand Challenges for engineering in the $21^{\text {st }}$ century. Students with cognitive differences may particularly respond to more personalized learning methods. One such avenue to enhance personalized learning is through research experience. The inherent open-endedness of research allows students a chance to think critically and creatively as there is not just one solution to a problem. This REU site is built on the model that allowing students to engage in activities that interest them, while allowing the freedom to explore and provide creative solutions, will increase their self-confidence and will produce impressive and valuable engineering products.

During the three years of the REU program, we have observed growth in students throughout the summer. At the beginning of the program, students tend to be hesitant, and less self-assured; they seemed unwilling to push the boundaries of conventional thinking. Throughout the program, the students gained confidence in themselves and their abilities, and demonstrated an increased willingness to explore creative thinking and out-of-the-box solutions. This boost in self-confidence was observed by both the mentors and the students themselves. By working in a strength-based educational setting, the students were able to gain an awareness and appreciation of their own strengths and see themselves as valuable, contributing members of a group. Based on the students' responses, the REU site was successful in increasing the participants' interest in remaining in engineering as well as pursuing graduate studies. By retaining these individuals, we are tapping into the potential of a highly underrepresented group that can help solve the multifaceted challenges of the future with a wider and more diverse approach to finding solutions.

One avenue for increasing diversity in engineering is making courses and engineering programs more inclusive for neurodiverse students. Students with cognitive differences, such as ADHD, may struggle within the confines of the traditional engineering education curriculum. Throughout the 
program we saw the students flourish in a research-based environment. This was demonstrated by the quality of the posters produced by the participants at the end of the program. Through multiple round table discussions, we determined that the students may perform better if course assignments are open-ended with limited instruction. Open-ended questions should be included in engineering curriculums to help all students practice critical thinking and brainstorming of creative solutions. Providing research opportunities which offer more flexibility in terms of thinking and problem solving styles to students who have challenges in standard education settings can improve engagement and retention. Providing research opportunities to undergraduate students early in their college careers can be pivotal in motivating students to graduate from engineering as well as consider graduate studies. We found that at the completion of the program, many of our students were willing to pursue engineering research at a graduate level. However, the heavy emphasis on GPA in the current graduate admission process on GPA may impede graduate studies of students with ADHD. As such, course designs and the graduate admissions process need to be revamped to consider neurodiversity as a key component of diversity before we can hope to have a workforce which reflects the heterogeneity of our society.

\section{Acknowledgements}

This research was a part of a project funded by the National Science Foundation (NSF), Division of Engineering Education and Centers under the Award Number 1461165. Any opinions, findings, and conclusions or recommendations expressed in this material are those of the authors and do not necessarily reflect the views of the National Science Foundation. Special thanks are given to Dr. Sally Reis, Dr. Susan Baum, and Dr. Rachael Gabriel for their expertise during seminars and workshops. 


\section{References}

1. Hülsheger UR, Anderson N, Salgado JF. Team-level predictors of innovation at work: a comprehensive metaanalysis spanning three decades of research. J Appl Psychol. 2009;94(5):1128-1145. doi:10.1037/a0015978.

2. Milliken FJ, Martins LL. Searching for common threads : Understanding the multiple effects of diversity in organizational groups. Acad Manag Rev. 2016;21(2):402-433.

3. Stahl GK, Maznevski ML, Voigt A, Jonsen K. Unraveling the effects of cultural diversity in teams: A metaanalysis of research on multicultural work groups. J Int Bus Stud. 2010;41(4):690-709. doi:10.1057/jibs.2009.85.

4. Glutting JJ, Youngstrom EA, Watkins MW. ADHD and college students: Exploratory and confirmatory factor structures with student and parent data. Psychol Assess. 2005;17(1):44-55. doi:10.1037/1040-3590.17.1.44.

5. Dupaul GJ, Weyandt LL, O’Dell SM, Varejao M. College students with ADHD: Current status and future directions. J Atten Disord. 2009;13(3):234-250. doi:10.1177/1087054709340650.

6. Heiligenstein E, Guenther G, Levy A, Savino F, Fulwiler J. Psychological and academic functioning in college students with attention deficit hyperactivity disorder. J Am Coll Heal. 1999;47(4):181-185. doi:10.1080/07448489909595644.

7. Frazier TW, Youngstrom EA, Glutting JJ, Watkins MW. ADHD and Achievement: Meta-Analysis of the Child, Adolescent, and Adult Literatures and a Concomitant Study With College Students. J Learn Disabil. 2007;40(1):49-65. doi:10.1177/00222194070400010401.

8. Bridgett DJ, Walker ME. Intellectual functioning in adults with ADHD: a meta-analytic examination of full scale IQ differences between adults with and without ADHD. Psychol Assess. 2006;18(1):1-14. doi:10.1037/1040-3590.18.1.1.

9. Lewandowski LJ, Lovett BJ, Codding RS, Gordon M. Symptoms of ADHD and academic concerns in college students with and without ADHD diagnoses. J Atten Disord. 2008;12(2):156-161. doi:10.1177/1087054707310882.

10. White HA, Shah P. Scope of semantic activation and innovative thinking in college students with ADHD. Creat Res J. 2016;28(3):275-282. doi:10.1080/10400419.2016.1195655.

11. White HA, Shah P. Creative style and achievement in adults with attention-deficit/hyperactivity disorder. Pers Individ Dif. 2011;50(5):673-677. doi:10.1016/j.paid.2010.12.015.

12. White HA, Shah P. Uninhibited imaginations: Creativity in adults with Attention-Deficit/Hyperactivity Disorder. Pers Individ Dif. 2006;40(6):1121-1131. doi:10.1016/j.paid.2005.11.007.

13. Barkley RA, Murphy K, Kwasnik D. Psychological adjustment and adaptive impairments in young adults with ADHD. J Atten Disord. 1996;1(1):41-54. doi:10.1177/108705479600100104.

14. Rothstein A. Mental Disorder or Neurodiversity? New Atl. 2012:99-115.

15. Sumner K, Brown T. Neurodiversity and human resource management: Employer challenges for applicants and employees with learning disabilities. Psychol J. 2015;18(2):77-85. doi:10.1037/mgr0000031.

16. Williams J, Taylor E. The evolution of hyperactivity, impulsivity and cognitive diversity. $J$ R Soc Interface. 2006;3(8):399-413. doi:10.1098/rsif.2005.0102.

17. Rentenbach B, Prislovsky L, Gabriel R. Valuing differences:: Neurodiversity in the classroom. Phi Delta Kappan. 2017;98(8):59-63. doi:10.1177/0031721717708297.

18. Armstrong T. The Myth of the Normal Brain: Embracing Neurodiversity. AMA J Ethics. 2015;17(4):348-352. doi:10.1001/journalofethics.2015.17.4.msoc1-1504.

19. Passow HJ, Passow $\mathrm{CH}$. What Competencies Should Undergraduate Engineering Programs Emphasize? A Systematic Review. J Eng Educ. 2017;106(3):475-526. doi:10.1002/jee.20171.

20. Cropley DH. Promoting creativity and innovation in engineering education. Psychol Aesthetics, Creat Arts. 2015;9(2):161-171. doi:10.1037/aca0000008.

21. Sparks RL, Javorsky J, Philips L. College students classified with ADHD and the foreign language requirement. J Learn Disabil. 2004;37(2):169-178. doi:10.1177/00222194040370020701.

22. Bernold LE, Spurlin JE, Anson CM. Understanding our students: A longitudinal study of success and failure in engineering with implications for increased retention. $J$ Eng Educ. 2007;96(3):263-274. doi:10.1002/j.2168-9830.2007.tb00935.x.

23. Marra RM, Rodgers KA, Shen D, Bogue B. Leaving Engineering: A Multi-Year Single Institution Study. $J$ Eng Educ. 2012;101(1):6-27. doi:10.1002/j.2168-9830.2012.tb00039.x. 